\title{
Saudi Parents' Involvement in Children's Education during COVID-19
}

\author{
Dalal Bahanshal \\ Assistant Professor, English Language Institute, King Abdulaziz University \\ PO Box 4246, Jeddah 22442, Saudi Arabia
}

Received: October 15, 2021 Accepted: November 16, 2021 Published: November 27, 2021

doi:10.5296/jet.v9i1.19262

URL: https://doi.org/10.5296/jet.v9i1.19262

\begin{abstract}
The flare-up of coronavirus has reportedly put on many changes and wrecked chaos in almost all life aspects, economically, academically, and socially. School closure has led to homeschooling, where the responsibility of children's education was laid mainly in the parents' hands. Consequently, many parents were compelled to be significantly involved in their children's education. However, full parental engagement in children's education is seemed to be a comparatively new trend amongst Saudi parents. Drawing from existing literature on parents' involvement, this paper used a quantitative descriptive study through a survey method to access the experience of Saudi parents involved in homeschooling. A purposive sampling technique was used to recruit 51 Saudi parents.

The findings showed that even though Saudi parents have encountered some challenges, they are facilitating their children's learning and assisting them throughout the online learning process. Parents' support was identified in different areas such as ensuring students' attendance of online sessions, nurturing a good session flow, connecting with teachers and parents via WhatsApp group, and taking full responsibility for mongering their children during exams. The result provided a comprehensive set of recommendations not only to parents but also to schools to consolidate a good connection between especially in times of crisis. It is envisaged that the results of this study will enrich the literature about this phenomenon which seems relatively new not only in the context where this study was situated but worldwide due to the pandemic of coronavirus or other unforeseen circumstances.
\end{abstract}

Keywords: children's education, coronavirus, home schooling, parental involvement, Saudi Parents 


\section{Introduction}

At times of the pandemic, school lockdown was one of the preventative measures almost all countries worldwide have taken to contain the viral spread. As much as this initiative is considered the best solution to remedy the threat of the time, it has brought burdens for many parents and caused them fear and anxiety regarding their children's education. To combat the negative effect of school closure, online learning has been employed to endure the educational process for all levels of schooling. Transferring education from school to home, children's education has been laid on parents' shoulders at a much larger rate. Therefore, a partnership between home and school was indeed significant. However, moving to teach and learning to homes, parents' involvement is considered more complex than what parents, students, and teachers have experienced before.

According to Ntekane (2018), parental involvement refers to "a situation where parents are directly involved in the education of their children, they involve themselves and are involved by the school and teachers in the learning process of their children" (p.1). Closing down schools to protect children from catching the virus is a situation where parents have found themselves extensively involved in their children's education. Consequently, many struggled to maintain the continuity of the learning process as unprecedented challenges have occurred not only academically but also socially.

Apart from the different parenting skills, e.g., being a good model, encouraging, understanding, nurturing, many parents had to have a certain level of education to support their children academically. Parents' educational level is one of the influential factors that strongly lead children to succeed over the learning (Khajehpour \& Ghazvini; 2011; Sapungan $\&$ Sapungan, 2014). Parents had to master almost all subjects to deliver educational practices effectively. Along with that, they needed to have adequate pedagogical information and strategical instructions on the best way to educate their children (Hasler \& Leong, 2014).

As for the social aspects, many parents were concerned about the effect of social isolation on their children's well-being, how far it may impair their communal outgrowth, and to what extent children will endure the crisis of this pandemic. Studies have shown that the lack of social relationships may have immediate effects and a long-lasting impact on children's behavioral aspects and well-being (Lyyra et al., 2018; Sanders, 2020). Another issue is that the family's daily routine has been adjusted to cope with the different timing of the online sessions, which placed a level of disquietude for all parents in general and the working parents in particular. Regardless of the family's unpreparedness for the issues mentioned above and others, parents were worried about the quality of education their children receive during homeschooling. Therefore, many parents have been effectively involved in their children's education and endeavored to offer them the best version of homeschooling throughout these extraordinary circumstances. 


\subsection{Types of Parents Involvement}

Based on the results of many studies concluded by parents and teachers alike, a framework of six main types of parent involvement was identified. These are parenting that supports the home learning environment, communicating with schools, volunteering in different learning activities, learning at home, taking part in decision-making, and collaborating with the community (Epstein, 1995).

Some studies have documented parental involvement, which shows parents' significant role in their children's education. One of those is a study conducted in East Java by Hapsari and Fauziah (2020). The research's findings identified diverse types of parents' involvement. These are supporting, parents and school communication, homeschooling strategies, and finally, decision making. To some extent, the findings of the two researchers align with the framework discussed above by Epstein (1995). One of the exciting findings of this study is that mothers were more involved in homeschooling than fathers. However, the study at hand did not aim to compare the rate of mothers' or fathers' involvement as the concentration was targeted to the effort both parents put into their children's education. Parents can also help teachers by following up with homework, assignments, and different school activities. Another key to sustained good outcomes is to provide solutions for challenges faced in schools, academically or socially, through productive collaboration between home and school. Above all, being involved in children's education helps parents apprehend their children's development and effectively support them to cope with online learning.

Another study was taken part in the United States by a group of researchers in 2020. Garbe and her fellow researchers aimed to explore the difficulties faced by 122 parents during the school closure. The participants pointed to their struggle with balancing responsibilities, boosting the motivational level of their children, and achieving the best learning outcomes. The result found in the literature and the previous studies triggered this research, and the intention was geared towards investigating how Saudi parents dealt with remote learning during COVID-19.

\subsection{Effect of Parent Involvement}

The benefits of parents' involvement in their children's education are undeniable. Results of many studies have proven that parents' involvement leads to satisfactory children's academic achievement (Pinatoan, 2013; Hasan, 2020). Robust evidence has documented that communication between parents and schools, the home environment, and parental involvement in children's education has an overall effect on students' academic progress, hence their success (Drenovsky \& Cohen, 2012; Kabir \& Akter, 2014; Dowd et al., 2017). For one, students of involved parents, compared to others with disengaged ones, have positive attitudes towards education, low rate of absenteeism, high level of concentration, and are persistent to achieve the best result possible (Llamas \& Tuazon, 2016). However, they caution that constant checking on students' attendance and progress may make children feel untrusted, deteriorating the parent-children relationship. Another benefit of parents' involvement is raising students' self-esteem and awareness towards their future through parents-children mutual discussion and parental support. 
Being involved in children's education will help parents alleviate learning anxiety that students may experience either in the actual learning setting or during remote learning. Taking a crucial stand-in children's education will help parents mitigate the learning stress, understand their educational needs, and help them with their decisions and plans (Clinton \& Hattie, 2013). In turn, this will create a good rapport between children and their parents and strengthen the family bond for a better home environment.

Parental involvement will also reflect on students' behaviors as close parental attention may head off some delinquent actions and others related to destructive behaviors. Schools and teachers may experience less disruption from students whose parents have good connections with the school. Monitoring students' attendance by their parents will minimize the absence rate, thereby augmenting the academic achievement level (Llamas \& Tuazon, 2016). Notably, the educational level and social skills of students of involved parents are positively affected. All in all, the outcome of parental involvement can be regarded as stimulating, encouraging, and supporting.

\section{Study Purpose}

Considering the fact that Saudi parents' involvement in their children's education is relatively a new trend, this study was initiated to investigate the challenges Saudi parents met and the types of support they provided their children with when school doors were closed due to the epidemic. It is also hoped that the findings of this study will offer valuable recommendations to parents and stakeholders to safeguard the educational process against any unforeseen circumstances that may negatively affect children's education.

\section{Method}

\subsection{Study Participants}

For this study, purposive sampling was employed to recruit 51 Saudi parents of children in three different primary, intermediate, and high school levels. According to Zhi (2014), in purposive sampling, participants are chosen based on the researcher/s' professional judgment to offer deep insight and enrich our knowledge on the topic. This aligns with Yin (2011), who wrote: "purposive sampling is deliberate and will most likely yield the most relevant and plentiful data" (p.88). Additionally, participants are chosen according to their willingness to be involved and availability when the study is conducted. Data on participants is shown in the table below.

Table 1. Participant Demographic

\begin{tabular}{|c|c|c|c|c|c|c|c|c|c|c|c|}
\hline \multicolumn{2}{|c|}{ Parents' status } & \multicolumn{2}{|c|}{ Gender } & \multicolumn{4}{c|}{ Qualification } & \multicolumn{2}{c|}{ No. of Children } & \multicolumn{2}{c|}{ Employment Status } \\
\hline Joint & Single & Mother & Father & PhD & Master & BA & Diploma & 1 to 3 & $\begin{array}{c}4 \& \\
\text { above }\end{array}$ & On site & Home \\
\hline 38 & 13 & 40 & 11 & 4 & 6 & 26 & 15 & 24 & 27 & 28 & 23 \\
\hline
\end{tabular}




\subsection{Data Instruments \& Procedures}

A survey composed of three categories with a total of 16 questions was designed specifically for this research. The closed-ended items queried the struggle parents experienced and the assistance they provided during homeschooling. The survey with no consent form was sent via WhatsApp to 69 Saudi parents of different gender, marital status, and qualification. However, only 51 parents responded. The selected participants were not asked to fill in a consent form as their completion of the questionnaire was considered an approval to use the data for only the purpose of this study. Google Docs platform was utilized to ease the process of creating and administering the online questionnaire (Jones \& Blankenship, 2018). The main version of the questionnaire was written in English then translated into Arabic for the convenience of participants who are not proficient in the English language. The questionnaire was composed of 4 Likert-scale ranging from never, sometimes, frequently, always.

Analyzing the data, this research employs a descriptive approach using a survey method. According to McMillan \& Schumacher (2010), the descriptive analysis describes and summarizes data collected from the study respondents who existed in a specific situation. With this in mind, this approach was found best to offer insight into this relatively new phenomenon in the Saudi context and identify significant aspects related to the topic under investigation.

\section{Results and Discussion}

The outbreak of COVID-19 did not only negatively impact people's health and economy, but it also deprived students at all levels of learning opportunities at school. Closing down schools and shifting learning to homes caused parents worldwide to adapt daily family routines to cope with remote classes. Many teleworking parents and others have become academically responsible for educating their children at different levels of schooling. Therefore, this study aimed to investigate the struggle Saudi parents faced, the types of their involvement, and the support they provided to maintain a seamless and effective learning process during the times of Covid-19.

The questionnaire is composed of three categories: parent challenges, home learning support, and parent engagement. Based on the result, the data showed that nearly $98.00 \%$ of parents had encountered significant challenges which they had never experienced before school lockdown. Nevertheless, they showed their consideration about their children's education and adapted to the new learning style.

Table 2 illustrates to what extent parents' work, family's daily routine, social life, and parental responsibilities have been affected by the transition to remote learning formats. Based on the analysis, parents' most apparent challenges were adjusting their working hours with the times of online sessions, changing the daily routine, and maintaining normalcy. Indeed, managing time for both teleworking parents and those who work in their offices and adapting to the new lifestyle was one of the most often reported challenges which caused an additional burden to many parents. A similar result was found in other studies (Garbe et al., 2020; Koskela et al., 
2020). Furthermore, the school lockdown did not only negatively impact children's education but also on their social life.

A significant number of Saudi parents reported their concern about the social isolation their children were put into during the breakdown of the virus. It is well documented that social isolation may have a long-term negative impact on the child's well-being and self-esteem. This result aligns with past research (Coyle \& Dugan, 2012; Brooks et al., 2020), which proved that social isolation might trigger depressive symptoms, disruptive behaviors, sleeping disorders, and others more.

Table 2. Parent Challenges

\begin{tabular}{|c|l|c|c|c|c|}
\hline S.n & \multicolumn{1}{|c|}{ Statements } & $\begin{array}{c}\text { Never } \\
\%\end{array}$ & $\begin{array}{c}\text { Sometimes } \\
\%\end{array}$ & $\begin{array}{c}\text { Frequently } \\
\%\end{array}$ & $\begin{array}{c}\text { Always } \\
\text { \% }\end{array}$ \\
\hline $\mathbf{1}$ & $\begin{array}{l}\text { Category-I: Parent challenges } \\
\text { I have to change the family's daily }\end{array}$ & $\mathbf{0 . 0 0}$ & $\mathbf{1 5 . 6 8}$ & $\mathbf{2 5 . 4 9}$ & $\mathbf{5 8 . 8 2}$ \\
\hline $\mathbf{2}$ & $\begin{array}{l}\text { My work has been affected by the home } \\
\text { learning environment. }\end{array}$ & $\mathbf{5 . 8 8}$ & $\mathbf{5 . 8 8}$ & $\mathbf{9 . 8 0}$ & $\mathbf{7 8 . 4 3}$ \\
\hline $\mathbf{3}$ & $\begin{array}{l}\text { The family's social life has been affected } \\
\text { by the home learning environment. }\end{array}$ & $\mathbf{1 1 . 7 6}$ & $\mathbf{7 . 8 4}$ & $\mathbf{2 7 . 4 5}$ & $\mathbf{5 2 . 9 4}$ \\
\hline $\mathbf{4}$ & $\begin{array}{l}\text { I have to give up some of my parental } \\
\text { responsibilities to execute home } \\
\text { learning. }\end{array}$ & $\mathbf{9 . 8 0}$ & $\mathbf{9 . 8 0}$ & $\mathbf{3 3 . 3 3}$ & $\mathbf{4 7 . 0 5}$ \\
\hline
\end{tabular}

Being the primary learning agent for their children during this crisis, Saudi parents offered great support during online learning. Table 3 demonstrates that $76.47 \%$ of participants helped their children with online tools, and a relatively similar percentage helped with off-screen work, which was assigned daily (74.50\%). While $7.48 \%$ felt insecure teaching their children, $56.86 \%$ of parents had confidence in presenting and explaining the learning materials. The data present that a relatively small number of participants, about $11.76 \%$ and $3.92 \%$, who frequently and consistently, respectively, sought online resources to understand the learning materials before explaining them to their children. Such a low percentage could be ascribed to the educational level of the participants. However, Other studies have recognized a contradictory result where the parents could not offer academic help to their children due to their low qualifications (Mbukusa et al., 2017; Abuhammad, 2020).

Furthermore, a high percentage of Saudi parents, about $86.27 \%$, constantly and frequently motivated their children to take part in class discussion comparatively to $3.92 \%$ and $9.80 \%$ who never or sometimes, respectively, induce their children to be active participants during online sessions. Parents' support was also pointed out by high school American teachers who identified different types of parents' involvement, like motivating their children and managing the online schedules (Borup, 2016). To provide even more support, it was found that more than $80.00 \%$ of the participants always and frequently collaborated with other parents to 
discuss related issues to online sessions, which they may not do when their children were attending a physical school learning setting. Studies in different contexts have also found that parents formed groups to circulate valuable recommendations and advice amongst members (Bhamani et al., 2020, Razzaque, 2020).

Executing remote learning has put unprecedented challenges on parents and children alike. Aiming to support their children significantly, almost $96.00 \%$ of the Saudi parents reacted to the learning struggle and endeavored to be a source of comfort to their children who may face any burden caused by remote learning and social isolation. This result aligns with the findings of other research (Grabe et al., 2020). Considering the necessity of controlling children's behavior during online sessions, which may allow students to benefit significantly from the lesson, more than $80.00 \%$ of the participants reported their ability to manage their children's actions and control their temperament while lessons are taught.

Table 3. Home Learning Support

\begin{tabular}{|c|l|c|c|c|c|}
\hline S.n & \multicolumn{1}{|c|}{ Statements } & \multicolumn{1}{|c|}{$\begin{array}{c}\text { Never } \\
\%\end{array}$} & $\begin{array}{c}\text { Sometimes } \\
\%\end{array}$ & $\begin{array}{c}\text { Frequently } \\
\%\end{array}$ & $\begin{array}{c}\text { Always } \\
\%\end{array}$ \\
\hline & Category-II: Home learning support & & & & \\
\hline $\mathbf{5}$ & I offer help with homework and assignment. & $\mathbf{5 . 8 8}$ & $\mathbf{9 . 8 0}$ & $\mathbf{9 . 8 0}$ & $\mathbf{7 4 . 5 0}$ \\
\hline $\mathbf{6}$ & I help my child to use online tools. & $\mathbf{0 . 0 0}$ & $\mathbf{3 . 9 2}$ & $\mathbf{1 9 . 6 0}$ & $\mathbf{7 6 . 4 7}$ \\
\hline $\mathbf{7}$ & I have confident when teaching my child. & $\mathbf{7 . 8 4}$ & $\mathbf{5 . 8 8}$ & $\mathbf{2 9 . 4 1}$ & $\mathbf{5 6 . 8 6}$ \\
\hline $\mathbf{8}$ & $\begin{array}{l}\text { I seek online sources to understand the learning } \\
\text { materials. }\end{array}$ & $\mathbf{4 9 . 0 1}$ & $\mathbf{3 5 . 2 9}$ & $\mathbf{1 1 . 7 6}$ & $\mathbf{3 . 9 2}$ \\
\hline $\mathbf{9}$ & $\begin{array}{l}\text { I encourage my child participation during online } \\
\text { session. }\end{array}$ & $\mathbf{3 . 9 2}$ & $\mathbf{9 . 8 0}$ & $\mathbf{2 7 . 4 5}$ & $\mathbf{5 8 . 8 2}$ \\
\hline $\mathbf{1 0}$ & I discuss with my child his/her academic struggle. & $\mathbf{0 . 0 0}$ & $\mathbf{3 . 9 2}$ & $\mathbf{2 3 . 5 2}$ & $\mathbf{7 2 . 5 4}$ \\
\hline $\mathbf{1 1}$ & I control my child behavior during online session. & $\mathbf{5 . 8 8}$ & $\mathbf{9 . 8 0}$ & $\mathbf{2 5 . 4 9}$ & $\mathbf{5 8 . 8 2}$ \\
\hline $\mathbf{1 2}$ & $\begin{array}{l}\text { I collaborate with other parents to help our } \\
\text { children. }\end{array}$ & $\mathbf{1 . 9 6}$ & $\mathbf{1 5 . 6 8}$ & $\mathbf{3 3 . 3 3}$ & $\mathbf{4 9 . 0 1}$ \\
\hline
\end{tabular}

Shifting to an online learning mode has been a mixture of positives and negatives for many parents and children alike. Even though Saudi parents have faced some challenges to make up for the traditional learning environment, table 4 presents the great concern and responsibilities the Saudi parents showed while executing successful remote learning. More than $80.00 \%$ of the participants were available with their children during the new learning format to reinforce active class participation and ensure the flow of adequate home learning studies.

Another mainly reported type of engagement was engaging with the teachers during and after online sessions. Furthermore, as shown in Table 4, almost $80.00 \%$ of the participants constantly engaged with their children's teachers. This high ratio demonstrates the heedful the Saudi parents have shown to ensure the efficacy and the successful continuity of home learning. It is evident that the Saudi parents did not face difficulty communicating with their children's teachers, which controverts with those of Grabe et al. (2020) and Mbukusa et al. (2017), where the respondents reported having difficulties connecting with the teachers. 
Additionally, the analysis of the third category presented in the table below elucidated only $7.84 \%$ and $11.76 \%$ who either never or sometimes, respectively, were present with their children during online sessions. In comparison, the percentage increased to $31.37 \%$ and $49.01 \%$ of the participants who were frequently and consistently persistent to join their children when attending the sessions. Compared to other research, no significant divergence was found between the Saudi parents and others who spent a greater amount of time with their children during and after online sessions (Hasler et al., 2014).

Regarding parent involvement, the findings also presented that supervising children in times of online exams constituted the highest rate compared to other forms of the participants' involvement. More than $90.00 \%$ were frequently and consistently available in times of exams compared to less than $8.00 \%$ who were sometimes aiding their children while taking online exams. Such a home learning environment demonstrates the primary responsibilities of parents, which as such are the fundaments of positive parent-child-bond (Hasan, 2020).

Table 4. Parent Engagement

\begin{tabular}{|c|c|c|c|c|c|}
\hline S.n & Statements & $\begin{array}{c}\text { Never } \\
\%\end{array}$ & $\begin{array}{c}\text { Sometimes } \\
\%\end{array}$ & $\begin{array}{c}\text { Frequently } \\
\%\end{array}$ & $\begin{array}{c}\text { Always } \\
\%\end{array}$ \\
\hline & \multicolumn{5}{|l|}{ Category-III: Parent engagement } \\
\hline 13 & I attend the online session with my child. & 7.84 & 11.76 & 31.37 & 49.01 \\
\hline 14 & $\begin{array}{l}\text { I engage with the teacher during online } \\
\text { session. }\end{array}$ & 5.88 & 9.80 & 15.68 & 68.62 \\
\hline 15 & I engage with the teacher after online session. & 1.96 & 9.80 & 29.41 & 49.01 \\
\hline 16 & I supervise my child during the online exams. & $\mathbf{0 . 0 0}$ & 7.84 & 19.60 & 72.54 \\
\hline
\end{tabular}

The above-discussed result confirmed that the benefits of parent involvement should not be underrated. Most Saudi participants took full responsibility for their children's education to ensure that learning in this time of crisis was not compromised. Additionally, they had shown significant consideration for their children's wellbeing. Therefore, they had endeavored to minify some of the struggles their children may experience during this dilemma of homeschooling. Attending online sessions with their children, supervising them during exams, connecting with their teachers, and reinforcing communications with other parents are some steps that Saudi parents found to be conceivably achievable and effectively appropriate to retain the continuity of successful home studies.

The result of the current research has viewed some of the struggles and concerns Saudi parents had during online learning. Additionally, this research may benefit stakeholders who will thus determine how school support can be extended to reach all parents, thereby reinforcing their collaboration with their children's teachers, encouraging their involvement, improving their technical skills and supervision abilities of home learning. Even though the finding of this study seemed to be promising, it is a call for further research to investigate this 
relatively new trend in Saudi society by even including a larger sample and implementing another research approach to gain more insight into this phenomenon.

\section{Conclusion}

It is explicitly that during homeschooling, parents' effort is tantamount to that of teachers' where the former attempts to retain an effective pace of their children's education. Given the fact that the transition to remote learning was an abrupt change rather than gradual, it is of great significance to recognize the roadblocks that influence parents' involvement in their children's education while continuing education remotely. Understandably, most of the support parents provide during remote learning helps students cope with the absence of physical classroom settings. However, this wave of innovations in education may not always be appropriate for all students, especially those with uninvolved parents. Therefore, it is recommended that schools should be cognizant of the types of assistance parents may offer to their children and their capability to facilitate home learning. Positive and effective bonds between schools and parents during the physical classroom setting, in general, and in times of remote learning, in particular, may impede any aggravating educational crisis and intensify the learning deficiency amongst school children.

In summary, collaborating with children during online sessions and spending much time with them will strengthen the bond between parents and their children. In this entourage, children may hold their parents to be a source of comfort and turn to them in times of struggle. Indeed, it is of great significance for schools to highly consider the role parents have in children's academic achievement not only during online sessions but also with physical learning mode. Therefore, maintaining a positive connection with parents, stimulating them to be involved in the learning process, and supporting them to be helpful in their children's educational attainment are all significant steps that can yield benefits towards great success and prosperity of students.

\section{References}

Abuhammad, S. (2020). Barriers to distance learning during the COVID-19 outbreak: A qualitative review from parents' perspective. Heliyon, 6, (e05482), 1-5. https://doi.org/10.1016/j.heliyon.2020.e05482

Bhamani, S. H., Makhdoom, A., Bharuchi, V., Ali, N., Kaleem, S., \& Ahmed, D. (2020). Journal of Education and Educational Development 7(1), 09-26. https://doi.org/10.22555/joeed.v7i1.3260

Borup, J. (2016). Teacher perceptions of parental engagement at a Cyber high school. Journal of Research in Technology in Education, 48(2), 67-83. https://doi.org/10.1080/15391523.2016.1146560

Brooks, S., Webster, R., Smith, L., Woodland, L., Wessely, S., \& Greenberg, N. (2020). The psychological impact of quarantine and how to reduce it: rapid review of the evidence. Lancet, 395, 912-920. https://doi.org/10.1016/S0140-6736(20)30460-8 
Clinton, M. \& Hattie, J. (2013). New Zealand students' perceptions of parental involvement in learning and schooling. Retrieved from https://doi.org/10.1080/02188791.2013.786679

Coyle, C., \& Dugan, E. (2012). Social isolation, loneliness and health among older adults. Journal of Aging and Health, 24, 1346-1363. https://doi.org/10.1177/0898264312460275

Dowd, A., Friedlander, E., \& Jonason, C. (2017). Life wide learning for early reading development. New directions for child and adolescent development, (155), 31-49. https://doi.org/10.1002/cad.20193

Drenovsky, C., \& Cohen, I. (2012). The Impact of Homeschooling on the Adjustment of College Students. International Social Science Review, 87(1-2), 19-34.

Epstein, J. (1995). School/family/community partnerships. Phi Delta Kappan, 76(9), 701-713.

Garbe, A., Ogurlul, U., Logan, N., \& Cook, P. (2020). COVID-19 and Remote Learning: Experiences of Parents with Children during the Pandemic. American Journal of Qualitative Research, 4(3), 45-65. https://doi.org/10.29333/ajqr/8471

Hapsari, \& Fauziah, (2020). Parent's Involvement in Early Childhood Education during the Covid-19 Pandemic Period. Jurnal Pendidikan Progresif, 10(2), 162-172. https://doi.org/10.23960/jpp.v10.i2.202014

Hasan, S. (2020). Schools close, children free -parents face a new conundrum. Retrieved from

https://www.dawn.com/news/1540682/schools-close-children-free-parentsface-new-conundru $\mathrm{m}$

Hasler Waters, L., \& Leong, P. (2014). Who is teaching? New roles for teachers and parents in cyber charter schools. Journal of Technology and Teacher Education, 22(1), 33-56.

Jones, I., \& Blankenship, D. (2018). Learning styles, online courses, gender, and academic achievement of Hispanic students in higher education. Research in Higher Education Journal, 35,14 .

Kabir, A., \& Akter, F. (2014). Parental involvement in the secondary schools in Bangladesh: Challenges and a way forward. International Journal of Whole Schooling, 10(2), 21-38.

Khajehpour, M., \& Ghazvini, S. (2011). The role of parental involvement effect in children's academic performance. Procedia Social and Behavioural Sciences, 15, 1204-1208. https://doi.org/10.1016/j.sbspro.2011.03.263

Koskela, T., Pihlainen, K., Piispa-Hakala, S., Vornanen, R., \& Hämäläinen, J. (2020). Parents' Views on Family Resiliency in Sustainable Remote Schooling during the COVID-19 Outbreak in Finland. Sustainability, MDPI, 12, 1-20. https://doi.org/10.3390/su12218844

Llamas, A., \& Tuazon, A. (2016). School practices in parental involvement, its expected results and barriers in public secondary schools. International Journal of Educational Science and Research, 6(1), 69-78. 
Lyyra, N., Valimaa, R., \& Tynjala, J. (2018). Loneliness and subjective health complaints among school-aged children. Scand. J. Public Health, 46, 87-93. https://doi.org/10.1177/1403494817743901

Mbukusa, N., Kibuule, D., \& Lates, J. (2017). Overcoming barriers of isolation in distance learning: building a collaborative community in learning. Adv. Soc. Sci. Res. J., 4(17), 34-42. https://doi.org/10.14738/assrj.417.3478

McMillan, J., \& Schumacher, S. (2010). Research in Education evidence based inquiry.7th Ed. New Jersey: Pearson

Ntekane, A. (2018). Parental Involvement in Education. Retrieved from https://www.researchgate.net/publication/324497851

Pinantoan, A. (2013). The effect of parental involvement on academic achievement. Retrieved from https://www.teachthought. com/ 283539737.

Razzaque, A. (2020). School's out. Retrieved from https://www.thenews.com.pk/print/621813-school-s-out

Sanders, R. (2020). ESS Outline: Covid-19, social isolation and loneliness. Special Report Iriss. https://doi.org/10.31583/esss.20200422

Sapungan, G., \& Sapungan, R. (2014). Parental Involvement in Child's Education: Importance, Barriers and Benefits. Asian Journal of Management Sciences and Education, $3(2), 42-48$.

Zhi, H. (2014). A comparison of convenience sampling and purposive sampling. PubMed, 105-11.

\section{Copyright Disclaimer}

Copyright for this article is retained by the author(s), with first publication rights granted to the journal.

This is an open-access article distributed under the terms and conditions of the Creative Commons Attribution license (http://creativecommons.org/licenses/by/4.0/). 